\title{
Studies on Pesticides Mixture Degradation by White Rot Fungi
}

\author{
Sofia Gouma', Anastasia A. Papadaki ${ }^{*}$, George Markakis', \\ Naresh Magan², Dimitris Goumas' \\ 1 Department of Agriculture, School of Agriculture Food and Nutrition, Technological Educational Institute of \\ Crete, Stauromenos, PC 71410, Greece \\ 2 Cranfield Soil and Agrifood Institute, Cranfield University, College Road, Cranfield MK43 OAL, Bedfordshire, U.K. \\ * Corresponding author's e-mail: apapadaki@staff.teicrete.gr
}

\begin{abstract}
The capacity of five white rot fungi species to degrade linuron, metribuzin and chlorpyrifos when applied both as single pesticides and mixed together in different concentrations on nutritionally poor media was investigated. Our results suggested that Pleurotus ostreatus, Pycnoporus coccineus, Phlebiopsis gigatea and Trametes versicolor showed a remarkable tolerance to the pesticides, in all media tested. The $\mathrm{EC}_{50}$ values presented a noticeable difference in the mixtures as compared with the individual ones. The minimum growth rate in the mixture was obtained by $P$. ostreatus whereas P. coccineus appeared to be more efficient than the rest fungal isolates, when cultivated in the soil extract medium. P. coccineus, P. gigantea and T. versicolor produce high levels of polyphenol oxidase, but only $T$. versicolor was capable of decomposing linuron when combined with metribuzin and chlorpyrifos.
\end{abstract}

Keywords: Biodegradation; fungi; growth rate; pesticides mixture; soil extract

\section{INTRODUCTION}

Environmental protection has been one of the greatest interests to science and the general public in the recent decades. Contamination of both soil and aquatic surrounding constitutes a significant matter for the ecological balance [Gianfreda and Bollag, 2002]. The agricultural activities involving the spread of pesticides are one of the main anthropogenic causes that generate the soil pollution. The presence of these xenobiotic chemicals has gone up tremendously over the last decades, along with the increasing concern about their adverse effects on human health.

Linuron is a systemic, selective and substituted urea herbicide (phenyl-urea) used worldwide for pre- and post-emergence control of weeds in various agriculture crops. It forms a contaminant in soil (mainly adsorbed by the organic matter fraction of soil) and its residues have been detected in surface and ground waters [Caux, 1998]. Metribuzin is a pre- and post-emergent herbicide, which is registered primarily for the manage- ment of broad leaf and various grassy weeds of numerous agriculture cultivations. It is extremely soluble in water and moderates persistence in soils [Extoxnet, 1993], consequently, potential leaching and groundwater contamination can occur. Biodegradation is the main mechanism by which this chemical disappears from soil. Chlorpyrifos is a broad- spectrum organophosphate insecticide, commonly and widely used to protect against important insects on many crops worldwide. It is highly absorbed by soil and constitutes a contaminant of drinking water. Significant literature denoted that an extended range of aquatic and terrestrial environment is possibly contaminated with chlorpyrifos [Yang et al., 2006] which has accelerated the general public interest to find a secure and cost-efficient approach to disposal or detoxification of chlorpyrifos residues in the infected areas.

The control of public health hazards inclusive of pesticides remains an critical discipline of investigation. It is apparent that the microbialbased methods of polluted environments provide 
a cost-effective opportunity to present remediation techniques [Singleton, 1994]. Bioremediation, which requires the use of organisms to neutralize or remove contaminants, is a popular technology and has received increasing global consideration as an efficient biotechnological method to purify the polluted regions [Singh et al., 2006; Ogunbayo et al., 2018].

The approach of using fungi for pesticide depletion from soils holds a critical guarantee since Phanerochaete chrysosporium, in 1985, was demonstrated as being capable of mineralizing some of crucial environmental pollutants [Sasek, 2003]. The lignin degrading enzymatic system of the white rot fungus was considered responsible for this capacity. Other white rot fungal species, among them Trametes versicolor, were later characterized by a similar degrading ability [Sasek, 2003].

White rot fungi (WRF) are characterized by a number of benefits that may be exploited in the bioremediation techniques. As key components of their lignin-degrading structures are extracellular, these fungi can degrade insoluble chemicals substances such as lignin or a markedly diverse range of extremely steady or toxic ecological pollutants [Asgher et al., 2008]. Additionally, the substrates are fast colonized by the mycelial development and hyphal extension allows soil penetration, approaching the contaminants more efficiently than other microbes [Reddy and Mathew, 2001; Fragoeiro and Magan, 2008]. The aforementioned qualities may improve the natural, mechanical and enzymatic influence with the surroundings [Maloney, 2001]. In order to comprehend the degrading capability of WRF, it is essential to examine their ecological specialization. The abovementioned fungi, including the effectively degrading lignin species, constitute a physiological, rather than a taxonomic group [Pointing, 2001].

A significant amount of studies and reviews has been conducted about the degradation of pesticides in soils by WRF; nevertheless, most of these studies have only focused on an individual contaminant pesticide [Getenga et al., 2000; Koroleva et al., 2015]. However, under actual agricultural practices, pesticides are more commonly found in mixtures and possible interactions can occur with the soil systems [Chu, 2008]. Therefore, the research should be focused on the pesticide combination as well as on the applications of different concentrations as the degradation behaviour of an individual pesticide may be altered in the mixture.
The objectives of the present study were to investigate the capability of Phanerochaete chrysosporium, Pleurotus ostreatus, Pycnoporus coccineus, Phlebiopsis gigantea and Trametes versicolor cultured in different nutritionally poor media on the tolerance to the pesticides linuron, metribuzin and chlorpyrifos individually and as a mixture, the enzyme production of the abovementioned fungi and the differential breakdown of the pesticides mixtures.

\section{MATERIALS AND METHODS}

\section{Fungal Inoculants}

The WRF isolates, used in the present investigation and their reference number were: P. chrysosporium (R170), P. ostreatus (R14), P. coccineus (R180), P. gigantea (R174) and T. versicolor (R26). They were kept as plates on 3\% malt extract agar (MEA) for up to two months at $4^{\circ} \mathrm{C}$.

\section{Pesticides}

Analytical grades of each pesticide: linuron (1-methoxy-1-methyl-3 (3,4-dichlorophenyl) urea) MW:249.1, metribuzin (1,2,4-Triazin-5 (4H)-one,4-amino-6-(1,1-dimethylethyl)-3(methylthio) MW:214.29 and chlorpyrifos (O, O-diethyl1 O-3, 5,6-trichloro-2-pyridyl phos)phorothioate) MW:350.62 were supplied by Sigma Aldrich. Stock standards solutions containing $2000 \mathrm{mg} \mathrm{L}^{-1}$ of each compound were prepared by dissolving accurately weighed amounts in methanol and stored in darkness at $4^{\circ} \mathrm{C}$.

\section{Media and substrates}

The culture media used in this study were MEA and Minimal salts Medium Yeast (MMY) which is a Czapek modified salts medium and the exact ingredients were: $\mathrm{MgSO}_{4} 0.5 \mathrm{~g}, \mathrm{NaNO}_{3} 2 \mathrm{~g}$, $\mathrm{K}_{2} \mathrm{HPO}_{4} 0.14 \mathrm{~g}, \mathrm{KCl} 0.5 \mathrm{~g}, \mathrm{FeSO}_{4} \times 7 \mathrm{H}_{2} \mathrm{O} 0.01 \mathrm{~g}$, Yeast $0.5 \mathrm{~g}$, Agar $20 \mathrm{~g}$ in $1 \mathrm{~L}$ distilled water.

\section{Soil extract preparation}

The soil extract medium was prepared by mixing soil $(\mathrm{pH} 7.6$, organic matter $1.12 \%$, sand $54.6 \%$, silt $21.2 \%$ and clay $24.2 \%$ ) and distilled water in a $1: 1(\mathrm{w} / \mathrm{v})$ ratio, sterilized by autoclaving at $121^{\circ} \mathrm{C}$ for $30 \mathrm{~min}$, centrifuged and then 
autoclaved again under the same conditions. In order to solidify, technical agar $(2 \% \mathrm{w} / \mathrm{v})$ was supplemented to the soil extract.

\section{Fungi tolerance to pesticides}

In order to access the tolerance of the five WRF species to pesticides, three approaches were conducted. At the first, MEA and MMY minimal salts medium were fortified with $10 \mathrm{mg} \mathrm{L}^{-1}$ of each of the chemicals linuron, metribuzin and chlorpyrifos alone, thoroughly mixed and spread on the molten agar. Subsequently, the fungi were cultured in the MMY, which was modified by adding $30 \mathrm{mg} \mathrm{L}^{-1}$ of the three pesticides separately or mixed at 15 (5 mg L-1 of each pesticide) and $30 \mathrm{mg} \mathrm{L}^{-1}$ (10 mg L-1 of each pesticide). In the last approach, linuron, metribuzin and chlorpyrifos independently added to soil extract agar at 5, 25 and $625 \mathrm{mg} \mathrm{L}^{-1}$ or as pesticide mixture in the rate $0-70 \mathrm{mg} \mathrm{L}^{-1}$ (total mixture content consisted of equal amounts of each pesticide). Aliquots of $15 \mathrm{ml}$ were poured into $9 \mathrm{~cm}$ Petri dishes. The fungal mycelia (disc $0.4 \mathrm{~cm}$ ) of each isolate were transferred to all the plates and inoculated at $25^{\circ} \mathrm{C}$. Three replicates per treatment were conducted. The fungal growth was estimated on a daily basis by diametric measurements (expressed in $\mathrm{cm}$ ) of the colony at right angles to each other and recorded consecutively for 16 days. The radial growth rate and the inhibition percentage of the colony growth were obtained from linear regression slopes of the temporal growth curves. The effective dose of each pesticide for $50 \%$ inhibition of the fungal development $\left(\mathrm{EC}_{50}\right.$ values), with respect to the control cultures was determined for each isolate, in the soil extract agar. In all the assays, the temperature was $25^{\circ} \mathrm{C}$, since this is relevant to the Mediterranean region.

\section{Pesticide analysis on soil extract liquid culture}

The ability of the three fungal isolates $P$. coccineus, $P$. gigantea and $T$. versicolor to degrade the pesticide mixtures of linuron, metribuzin and chlorpyrifos in soil extract liquid culture was determined. The Petri plates (9-cm diameter) contained aliquots of $16 \mathrm{ml}$ of soil extract enriched with the three chemicals mixed at following levels $0,10,20,30,40$ and $50 \mathrm{mg} \mathrm{L}^{-1}$. A 6-mm agar plug of actively growing mycelium was inoculated in each plate and incubated at $25^{\circ} \mathrm{C}$, for 21 days. Controls without fungus inoculation were run for comparison. There were three replicate dishes and control per pesticide/fungus treatment. After the incubation period, the mycelium was filtered through filter paper (Whatman No 1). The fresh filtrate used for pesticide quantification by HPLC. The pesticide remaining in the plates was determined and presented as a percentage.

A quantitative analysis of the pesticides was carried out with a 2100 HPLC system equipped with a C-18 column $(250 \times 4 \mathrm{~mm})$, a DAD detector and an auto sampler. They were eluted using an isocratic mobile phase of acetonitrile: water at a ratio of 60: 40 , at a flow rate of $0.8 \mathrm{ml} \mathrm{min}{ }^{-1}$ and an injection volume of $20 \mu$. The total analysis time was 8 min per sample, in a single HPLC run. Linuron was detected by UV absorbance at $249 \mathrm{~nm}$, metribuzin at $293 \mathrm{~nm}$ and chlorpyrifos at $251 \mathrm{~nm}$. The retention times were 5.5, 3.2 and 5.2 minutes, respectively, and the detection limit was less of $0.1 \mathrm{mg} \mathrm{L}^{-1}$ for the compounds analysed. The coefficients of determination $\left(\mathrm{R}^{2}\right)$ of the calibration curves created for each pesticide in soil extract were higher than 0.99 for all the studied pesticides (Figure 1).

\section{Polyphenol oxidase assay}

The tested fungi were centrally inoculated in a medium consisting of $1 \%$ tannic acid, $2 \%$ Czapek Dox modified salt and $2 \%$ of bacto-agar [Rigling, 1995], enriched with linuron, metribuzin and chlorpyrifos individually at 10 and $20 \mathrm{mg} \mathrm{L}^{-1}$ and as a mixture in the same total concentrations were incubated at $25^{\circ} \mathrm{C}$ for 8 days. The formation of a brown coloration of the substrate around the colony suggested a positive activity of the fungi, which was measured by diametric estimations at right edges to each other. This reflected the laccase and catechol oxidase production.

\section{Direct visualization of biological lignin degradation}

In order to estimate the lignin degradation capacity of the isolates, the WRF were cultured in a lignin medium [Sundman and Nase, 1971] which was supplemented with total concentrations of the pesticides mixture (linuron, metribuzin and chlorpyrifos) of 0,15 and $30 \mathrm{mg} \mathrm{L}^{-1}$ and separately each compound at $30 \mathrm{mg} \mathrm{L}^{-1}$. The fungal isolates were inoculated in the centre of the plates and incubated at $25^{\circ} \mathrm{C}$ for 8 days. The clear zones 


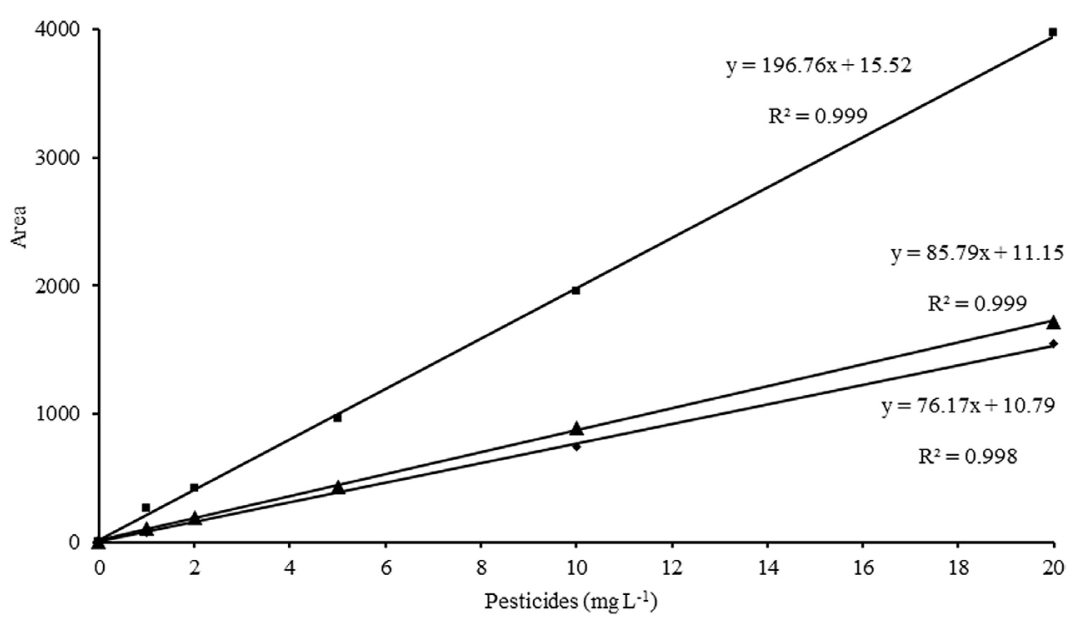

Figure 1. Standard curves and $r$-squared values for a mixture of linuron $\mathbf{m}$, metribuzin $\boldsymbol{\Delta}$ and chlorpyrifos in soil extract
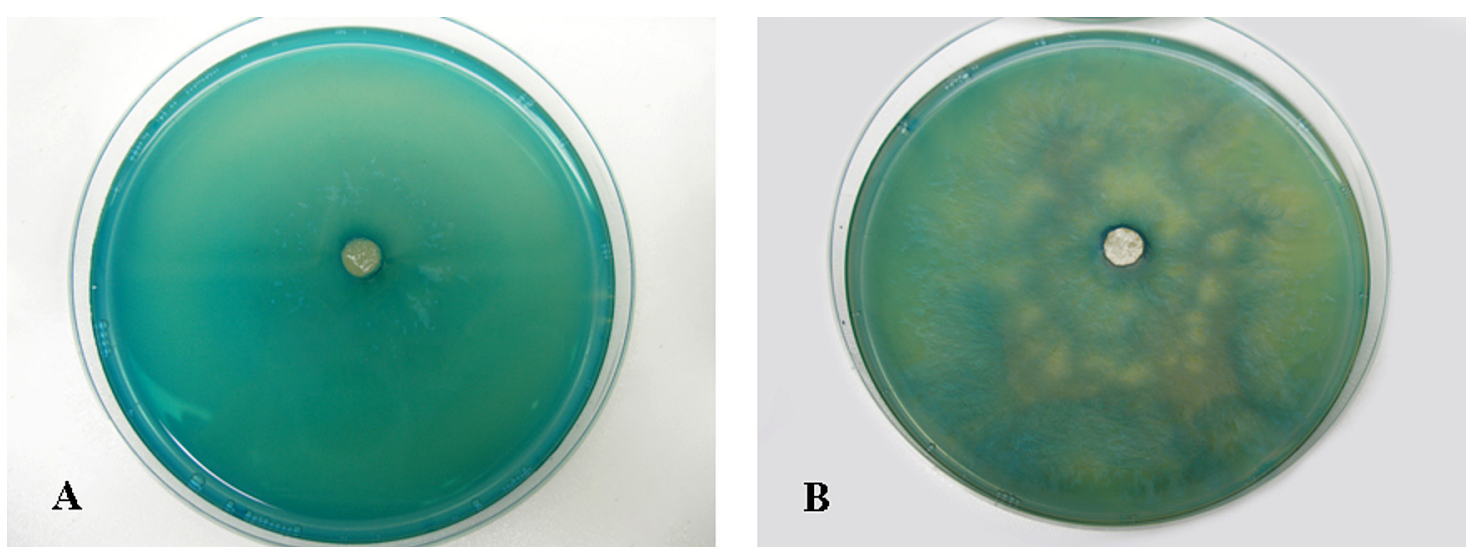

Plate 1.. Plate assay to assess potential ligninolytic activity of T. versicolor (B) in relation to the control (A).

around the growth area of the fungi implied an intense lignin degradation.

\section{Data handling and statistics}

The data were submitted to the analysis of variance (ANOVA) using SPSS (version 11). Tukey's test was performed for the comparison between means at the significant level $\mathrm{p}=0.05$. Standard error of means is shown as vertical bars in the figures and indicated in tables as \pm SE.

\section{RESULTS}

\section{In vitro fungi tolerance to pesticides in different media}

All the fungi tested in this study, presented a quite good growth on MMY in relation to the MEA. We observed a highly significant interac- tion $(p<0.001)$ between the pesticides and the fungi for all media. The Tukey's test revealed that $P$. chrysosporium exhibited the optimum growth rate in the presence of $10 \mathrm{mg} \mathrm{L}^{-1}$ linuron, metribuzin and chlorpyrifos when compared with the rest fungi, in all cases (Table 1).

Remarkably, the above-mentioned isolate was highly affected by the pesticides mixture (30 $\mathrm{mg} \mathrm{L}^{-1}$ total concentration) as well as the same concentration of linuron, metribuzin and chlorpyrifos apart. More specifically, P. chrysosporium grew successfully on control treatment $\left(1.09 \mathrm{~cm} \mathrm{day}^{-1}\right)$ whereas its growth rate decreased to $0.08 \mathrm{~cm} \mathrm{day}^{-1}$ when the culture medium was treated with chlorpyrifos at dose of $30 \mathrm{mg} \mathrm{L}^{-1}$ and to $0.09 \mathrm{~cm} \mathrm{day}^{-1}$ at $30 \mathrm{mg} \mathrm{L}^{-1}$ of the mixture (Table 2). This fungal isolate showed high sensitivity to the tested pesticides although it was observed to have the capacity to metabolize a number of important toxic pollutants [Sasek, 2003]. The growth rate of $P$. ostreatus was not influenced by 
Table 1. Growth rates $\left(\mathrm{cm} \mathrm{day}^{-1}\right)$ of the tested fungi on MEA (Malt Extract Agar) and MMY (Czapek salts modified medium) in the presence of $10 \mathrm{mg} \mathrm{L}^{-1}$ linuron, metribuzin and chlorpyrifos at $25^{\circ} \mathrm{C}$. SE of means of three replicates was $< \pm 0.01$ at $\mathrm{p}<0.05$.

\begin{tabular}{|c|c|c|c|c|}
\hline \multirow{2}{*}{ Fungi } & \multicolumn{4}{|c|}{ MEA } \\
\hline & Linuron & Metribuzin & Chlorpyrifos & Ctl \\
\hline P. chrysosporium & 1.35 & 1.57 & 1.42 & 1.55 \\
\hline P. ostreatus & 0.33 & 0.68 & 0.52 & 0.69 \\
\hline P. coccineus & 0.53 & 0.61 & 0.43 & 0.60 \\
\hline P. gigantea & 0.66 & 0.90 & 0.81 & 0.89 \\
\hline T. vercicolor & 0.72 & 0.79 & 0.78 & 0.78 \\
\hline \multicolumn{5}{|c|}{ MMY } \\
\hline P. chrysosporium & 0.96 & 1.17 & 0.88 & 1.26 \\
\hline P. ostreatus & 0.34 & 0.37 & 0.31 & 0.44 \\
\hline P. coccineus & 0.44 & 0.41 & 0.27 & 0.48 \\
\hline P. gigantea & 0.38 & 0.57 & 0.47 & 0.53 \\
\hline T. vercicolor & 0.78 & 0.70 & 0.52 & 0.77 \\
\hline
\end{tabular}

the addition of metribuzin $\left(30 \mathrm{mg} \mathrm{L}^{-1}\right)$ compared with the control $\left(0.38 \mathrm{~cm} \mathrm{day}^{-1}\right)$ whereas it was reduced to $0.13 \mathrm{~cm}$ day $^{-1}$ under the pesticides mixture (Table 2). The growth rate of all tested fungi was statistically significant and decreased with the increase of the concentration from 15 to 30 $\mathrm{mg} \mathrm{L}^{-1}$ of the pesticide mixture (Table 2); this influence depended on the presence of an individual or mixture of pesticides.

Figure 2 displays the comparison of the percentage inhibition among the five fungal inoculants. P. chrysosporium was very sensitive in all pesticides individually as in the mixture of $30 \mathrm{mg} \mathrm{L}^{-1}$ of them showing $80-90 \%$ inhibition. P. ostreatus had a very good growth in metribuzin, almost $20 \%$ suppress in chlorpyrifos, while in linuron and the mixture of $30 \mathrm{mg}$ $\mathrm{L}^{-1}$ presented a remarkable inhibition $(>60 \%)$. $P$. gigantea showed about $20 \%$ inhibition in all treatments. The mixtures of all pesticides at total concentration of $30 \mathrm{mg} \mathrm{L}^{-1}$ were not noticeably influenced the growth of $T$. versicolor and $P$. coccineus. There were marked differences between $T$. versicolor and $P$. coccineus tolerance to the three different pesticides alone. Specifically, T. versicolor showed $50 \%$ inhibition in linuron and chlorpyrifos, while in metribuzin had no inhibition. $P$. coccineus also exhibited a remarkable growth in linuron, while it showed an almost $20 \%$ and $45 \%$ inhibition to metribuzin and chlorpyrifos, respectively.

\section{WRF studies on soil extract}

P. ostreatus, P. coccineus, P. gigantea and T. versicolor were used in the soil extract studies due to the high sensitivity of $P$. chrysosporium to the mixture of linuron, metribuzin and chlorpyrifos. The growth of these fungal species on the soil extract is presented in Table 3. Linuron at $125 \mathrm{mg}$ $\mathrm{L}^{-1}$ entirely inhibited the growth of all tested fungi while chlorpyrifos at $125 \mathrm{mg} \mathrm{L}^{-1}$ significantly decreased their growth. Contrariwise, in the same concentration of metribuzin $T$. versicolor appeared very tolerant, $P$. gigantea and $P$. ostreatus presented high sensitivity whereas the growth of $P$. coccineus was reduced bz almost $50 \%$. As far as the pesticide mixtures are concerned, the

Table 2. Growth rates $\left(\mathrm{cm} \mathrm{day}^{-1}\right)$ of the tested fungi on MMY (Czapek modified salts medium) in the presence of $30 \mathrm{mg} \mathrm{L}^{-1}$ linuron, metribuzin and chlorpyrifos, individually and as mixture (15 and $30 \mathrm{mg} \mathrm{L}^{-1}$ total concentration) at $25^{\circ} \mathrm{C}$. SE of means of three replicates was $< \pm 0.01$ at $\mathrm{p}<0.05$.

\begin{tabular}{|l|c|c|c|c|c|c|}
\hline \multicolumn{1}{|c|}{ Fungi } & Linuron & Metribuzin & Chlorpyrifos & Ctl & $\begin{array}{c}\text { mixture } \\
\mathrm{mg} \mathrm{L}^{-1}\end{array}$ & $\begin{array}{c}\text { mixture } 30 \\
\mathrm{mg} \mathrm{L}^{-1}\end{array}$ \\
\hline P. chrysosporium & 0.04 & 0.15 & 0.08 & 1.09 & 0.03 & 0.09 \\
\hline P. ostreatus & 0.14 & 0.38 & 0.34 & 0.38 & 0.18 & 0.13 \\
\hline P. coccineus & 0.55 & 0.43 & 0.28 & 0.53 & 0.48 & 0.45 \\
\hline P. gigantea & 0.33 & 0.38 & 0.37 & 0.47 & 0.34 \\
\hline T. vercicolor & 0.36 & 0.79 & 0.36 & 0.79 & 0.72 & 0.72 \\
\hline
\end{tabular}




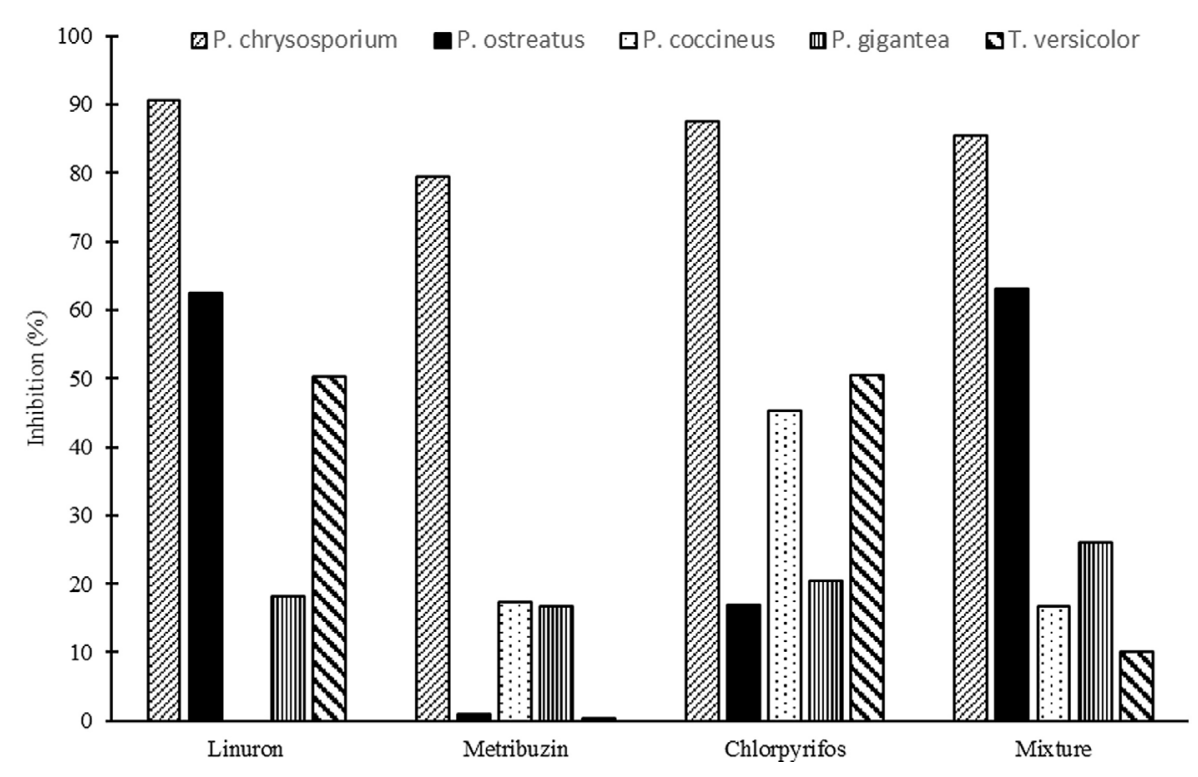

Figure 2. Mean growth inhibition (\%) observed for the tested fungi growing in MMY (Czapek modified salts medium) supplemented with $30 \mathrm{mg} \mathrm{L}^{-1}$ of linuron, metribuzin and chlorpyrifos individually and as a mixture, at $25^{\circ} \mathrm{C}$.

growth rates of the tested fungi were decreased with their increasing concentrations (Table 3 ).

The $\mathrm{EC}_{50}$ values of the pesticides that caused a $50 \%$ reduction of fungal growth, showed a noticeable difference in the mixtures as compared with the individual ones. A $50 \%$ reduction of T. versicolor was noticed with $292.2 \mathrm{mg} \mathrm{L}^{-1}$ of metribuzin, while in the pesticide mixture the $\mathrm{EC}_{50}$ was decreased at $54.1 \mathrm{mg} \mathrm{L}^{-1}$. P. ostreatus had the lowest growth rate as in the mixture as in the linuron, whereas $P$. coccineus presented an elevated tolerance compared with the rest of the fungi (Table 4).

The response of $P$. coccineus, $P$. gigantea and $T$. versicolor to degradation of the pesticide mixtures is provided in Table 5. Regarding linuron, $T$. versicolor presented a remarkable ability to degrade it even in the highest concentration (50 $\mathrm{m} \mathrm{L} \mathrm{L}^{-1}$ ). Two different subsets were revealed according to Tukey's test, the concentrations 10 and $20 \mathrm{mg} \mathrm{L}^{-1}$ of the pesticides mixture belonged to the first and the rest $\left(30,40\right.$ and $\left.50 \mathrm{mg} \mathrm{L}^{-1}\right)$

Table 3. Growth rates (means $\pm \mathrm{SE}, \mathrm{n}=3$ ) of the tested fungi incubated in soil extract agar supplemented with linuron, metribuzin and chlorpyrifos $\left(0,25,125 \mathrm{mg} \mathrm{L}^{-1}\right)$ and as a mixture $\left(0-70 \mathrm{mg} \mathrm{L}^{-1}\right)$ at $25^{\circ} \mathrm{C}$.

\begin{tabular}{|c|c|c|c|c|c|}
\hline \multirow{2}{*}{ Pesticides } & \multirow{2}{*}{ Concentration (mg L-1) } & \multicolumn{4}{|c|}{ Growth rate $\left(\mathrm{cm}\right.$ day $\left.{ }^{-1}\right)$} \\
\hline & & P. ostreatus & P. coccineus & P. gigantea & T. versicolor \\
\hline \multirow{4}{*}{ Linuron } & 0 & $0.3 \pm 0.00$ & $0.5 \pm 0.01$ & $0.6 \pm 0.01$ & $0.7 \pm 0.01$ \\
\hline & 5 & $0.3 \pm 0.03$ & $0.5 \pm 0.01$ & $0.6 \pm 0.01$ & $0.7 \pm 0.00$ \\
\hline & 25 & N. G. ${ }^{a}$ & $0.4 \pm 0.00$ & $0.4 \pm 0.01$ & $0.4 \pm 0.01$ \\
\hline & 125 & N. G. & N. G. & N. G. & N. G. \\
\hline \multirow{3}{*}{ Metribuzin } & 5 & $0.3 \pm 0.00$ & $0.4 \pm 0.00$ & $0.6 \pm 0.01$ & $0.7 \pm 0.02$ \\
\hline & 25 & $0.3 \pm 0.00$ & $0.5 \pm 0.01$ & $0.5 \pm 0.04$ & $0.7 \pm 0.01$ \\
\hline & 125 & $0.1 \pm 0.01$ & $0.3 \pm 0.00$ & N. G. & $0.5 \pm 0.07$ \\
\hline \multirow{3}{*}{ Chlorpyrifos } & 5 & $0.3 \pm 0.01$ & $0.3 \pm 0.01$ & $0.6 \pm 0.01$ & $0.6 \pm 0.00$ \\
\hline & 25 & $0.2 \pm 0.01$ & $0.2 \pm 0.01$ & $0.5 \pm 0.02$ & $0.5 \pm 0.00$ \\
\hline & 125 & $0.1 \pm 0.01$ & $0.1 \pm 0.00$ & $0.3 \pm 0.06$ & $0.3 \pm 0.14$ \\
\hline \multirow{7}{*}{ Mixture } & 10 & $0.3 \pm 0.01$ & $0.5 \pm 0.01$ & $0.6 \pm 0.02$ & $0.6 \pm 0.02$ \\
\hline & 20 & $0.2 \pm 0.01$ & $0.5 \pm 0.01$ & $0.5 \pm 0.02$ & $0.5 \pm 0.00$ \\
\hline & 30 & $0.1 \pm 0.01$ & $0.4 \pm 0.02$ & $0.5 \pm 0.00$ & $0.5 \pm 0.01$ \\
\hline & 40 & $0.1 \pm 0.02$ & $0.4 \pm 0.01$ & $0.4 \pm 0.05$ & $0.5 \pm 0.01$ \\
\hline & 50 & N. G. & $0.3 \pm 0.00$ & $0.3 \pm 0.03$ & $0.3 \pm 0.02$ \\
\hline & 60 & N. G. & $0.3 \pm 0.00$ & $0.4 \pm 0.02$ & $0.3 \pm 0.02$ \\
\hline & 70 & N. G. & $0.3 \pm 0.00$ & $0.4 \pm 0.01$ & $0.3 \pm 0.03$ \\
\hline
\end{tabular}


Table 4. Concentration of linuron, metribuzin and chlorpyrifos individually and as a mixture that causes a $50 \%$ reduction in fungal growth ( $\mathrm{EC}_{50}$ values) of the tested fungi growing on soil extract agar.

\begin{tabular}{|c|c|c|c|c|}
\hline \multirow{2}{*}{ Fungi } & Linuron & Metribuzin & Chlorpyrifos & Mixture \\
\cline { 2 - 5 } & \multicolumn{4}{|c|}{ Concentration $\left(\mathrm{mg} \mathrm{L}^{-1}\right)$} \\
\hline P. ostreatus & 35.1 & 101.2 & 79.6 & 27.9 \\
\hline P. coccineus & 64.7 & 123.5 & 61.1 & 75.5 \\
\hline P. gigantea & 62.6 & 95.2 & 106.2 & 51.7 \\
\hline T. versicolor & 63.9 & 292.2 & 107.4 & 54.1 \\
\hline
\end{tabular}

included to the second subset. The remaining (\%) metribuzin was very high in all mixtures regardless of the tested isolates (Table 5). Significant differences in the degradation rates were observed between the fungal isolates with regard to the tested concentrations of chlorpyrifos. $P$. coccineus and $P$. gigantea had almost a $60 \%$ disappearance rate while T. versicolor exhibited $85.7 \%$ at $10 \mathrm{mg} \mathrm{L}^{-1}$ of this pesticide. T. versicolor and $P$. gigantea failed to sufficiently degrade the highest concentrations of chlorpyrifos (30-50 $\left.\mathrm{mg} \mathrm{L}^{-1}\right)$. $P$. gigantea and $P$. coccineus indicated very low degradation rates in all treatments $(\mathrm{p}=0.01)$.

\section{Polyphenol oxidase production}

The fungal isolates formed activity halos in all studied concentrations of pesticides without indicating significant differences between them. Polyphenol oxidase production by $P$. coccineus, $P$. gigantea and T. versicolor expressed as radius of enzyme activity halo is depicted in Figure 3. $P$. coccineus demonstrated an increased polyphenol oxidase activitył however, it was not significantly influenced by the dose of linuron $(p=0.2)$, metribuzin $(p=0.138)$ and chlorpyrifos $(p=0.77)$ when applied separately, although in the case of their mixture, a relative decrease was noticed $(\mathrm{p}=0.036)$. P. gigantea exhibited the enzyme activity under the occurrence of the mixed pesticides $(\mathrm{p}=0.157)$ and linuron alone $(p=0.163)$, irrespectively of their dosage. The concentrations of metribuzin and chlorpyrifos did not considerably influence the polyphenol oxidase composition ( $\mathrm{p}=0.032$ and $\mathrm{p}=0.018$, respectively). T. versicolor showed the greatest enzyme activity in almost all cases. The polyphenol oxidase formation was not influenced by metribuzin $(p=0.422)$ whereas linuron, chlorpyrifos and the mixed compounds lowered the enzymatic activity $(\mathrm{p}<0.001)$.

\section{Lignolytic enzymes production}

The present investigation was undertaken to examine the enzymes produced by the three fungal isolates $P$. coccineus, $P$. gigantea and T. versicolor as well as the potential impact of

Table 5. Linuron, metribuzin and chlorpyrifos remaining (\%) (means $\pm \mathrm{SE}, \mathrm{n}=3$ ) in soil extract, initially supplemented with a mixture of pesticides of $10-50 \mathrm{mg} \mathrm{L}^{-1}$, after 21 days of incubation at $25^{\circ} \mathrm{C}$.

\begin{tabular}{|c|c|c|c|c|}
\hline \multirow{3}{*}{ Pesticides } & $\begin{array}{c}\text { Initial concentration of } \\
\text { mixture }\left(\mathrm{mg} \mathrm{L}^{-1}\right)\end{array}$ & \multicolumn{3}{|c|}{ Remaining pesticide (\%) } \\
\cline { 2 - 5 } & 10 & 6. coccineus & P. gigantea & T. versicolor \\
\hline \multirow{4}{*}{ Linuron } & 20 & $71.8 \pm 1.9$ & $73.9 \pm 2.7$ & $14.5 \pm 5.8$ \\
\cline { 2 - 5 } & 30 & $77.0 \pm 3.1$ & $82.5 \pm 6.5$ & $21.8 \pm 5.3$ \\
\cline { 2 - 5 } & 40 & $63.5 \pm 1.7$ & $51.8 \pm 11.2$ & $41.1 \pm 3.0$ \\
\cline { 2 - 5 } & 50 & $76.6 \pm 1.0$ & $69.7 \pm 4.2$ & $38.2 \pm 2.8$ \\
\hline \multirow{4}{*}{ Metribuzin } & 10 & $57.7 \pm 3.4$ & $89.6 \pm 6.5$ & $39.3 \pm 2.6$ \\
\cline { 2 - 5 } & 20 & $82.3 \pm 6.0$ & $93.5 \pm 2.0$ & $83.2 \pm \pm 3.0$ \\
\cline { 2 - 5 } & 30 & $84.1 \pm 1.8$ & $100 \pm 0.0$ & $80.1 \pm 9.21$ \\
\cline { 2 - 5 } & 40 & $92.5 \pm 1.5$ & $100 \pm 0.0$ & $84.1 \pm 2.26$ \\
\hline \multirow{5}{*}{ Chlorpyrifos } & 50 & $91.4 \pm 3.3$ & $100 \pm 0.0$ & $100 \pm 0.0$ \\
\cline { 2 - 5 } & 10 & $41.3 \pm 7.8$ & $39.5 \pm 13.7$ & $14.3 \pm 8.7$ \\
\cline { 2 - 5 } & 20 & $59.4 \pm 5.0$ & $52.3 \pm 7.8$ & $37.4 \pm 9.9$ \\
\cline { 2 - 5 } & 30 & $59.2 \pm 1.3$ & $69.1 \pm 1.6$ & $78.3 \pm 10.7$ \\
\cline { 2 - 5 } & 40 & $45.1 \pm 7.3$ & $86.9 \pm 2.5$ & $94.6 \pm 0.8$ \\
\hline
\end{tabular}



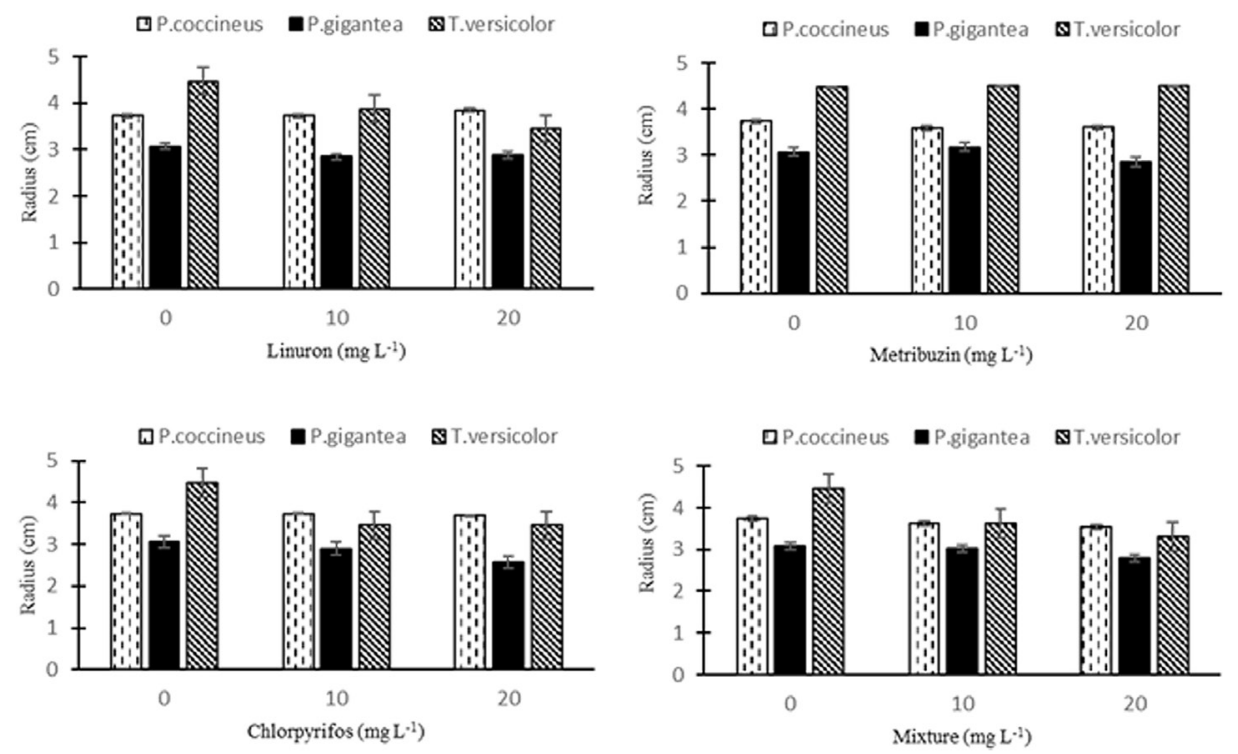

Figure 3. Effect of linuron, metribuzin, chlorpyrifos individually and as a mixture $\left(0,10\right.$ and $\left.20 \mathrm{mg} \mathrm{L}^{-1}\right)$ on polyphenol oxidase activity by $P$. coccineus, $P$. gigantea and $T$. versicolor at $25^{\circ} \mathrm{C}$ (expressed as radius of enzyme activity halo means $\pm \mathrm{SE}, \mathrm{n}=3$ ).

pesticides on this development. In spite of the fact that $P$. coccineus and P. gigantea presented good growth in the medium used, they did not show decolouration under the conditions of this study.

The ligninolytic activity of $T$. versicolor was expressed as diffused spots compared to control (Plate 1); thus it was difficult to measure. Similar appearance was noticed in all treatments. T. versicolor presented pronounced ligninolytic activity; however, it was not influenced by concentrations of pesticides or their mixture.

\section{DISCUSSION}

The research concerning the growth rates of fungi could be crucial for the extrapolation of the potential colonization ability in the discipline due to great knowledge provided on the progress of a fungus capability to colonize the substrate. Besides, the growth rates may suggest which species could be dominant over a particular substrate; the rapidly developing species have a favourable position in comparison with slower isolates due to access and effectively usage of resources sooner than their competitors [Magan and Lacey, 1984]. Consequently, the enhanced fungal growth may benefit the imported species to predominate over the native soil organisms [Singleton, 2001].

In the screening experiments, the effects of different culture media on the growth of the five fungal inoculants (P. chrysosporium, P. ostrea- tus, P. coccineus, P. gigantea and T. versicolor) and their tolerance to the pesticides linuron, metribuzin and chlorpyrifos were investigated. All isolates demonstrated a good development in the MMY and soil extract (a nutritionally weak medium in order to imitate the nutrient availability in soil) in relation to the conducive medium MEA. The growth of $T$. versicolor was not influenced in MMY, whereas it was decreased by approximately $20 \%$ for $P$. chrysosporium and $P$. coccineus and $40 \%$ for P. ostreatus and P. gigantea in the same medium.

The response of all tested fungi to the pesticides was affected by the dose of the chemicals and the individual or mixed application of them in a weak medium. Particularly, P. chrysosporium was very sensitive to linuron while $P$. coccineus and $P$. gigantea were the most tolerant fungi to $30 \mathrm{mg} \mathrm{L}^{-1}$ concentration of this pesticide, demonstrating $0 \%$ and $20 \%$ inhibition, respectively.

In relation to chlorpyrifos $\left(30 \mathrm{mg} \mathrm{L}^{-1}\right)$, $P$. chrysosporium presented the highest sensitivity, whereas $P$. ostreatus showed the best tolerance, as compared to all the rest fungi. All the isolates, excluding $P$. chrysosporium, exhibited a very good ability to tolerate both metribuzin alone and pesticides mixture of $30 \mathrm{mg} \mathrm{L}^{-1}$, although all the species demonstrated a noticeable growth reduction. These outcomes distinctly contribute to the background information on the capability of fungi to grow in nutritionally poor media in the presence of the pesticides. 
The findings derived from the growth of the fungal isolates on the soil extract medium and the $\mathrm{EC}_{50}$ determination confirmed the initial screenings. Specifically, all species showed sensitivity to the elevated linuron levels, whereas they tolerated metribuzin considerably. The most sensitive fungi to chlorpyrifos were $P$. ostreatus and $P$. coccineus when compared to the others. $P$. ostreatus was extremely sensitive in the mixture of the pesticides and was not included in subsequent studies concerning the production of lignolitic enzymes as well as the degradation of pesticides. Overall, the results clearly indicated a remarkable decrease of the fungal growth under the mixed pesticides, with respect to their individual existence. Consequently, it is imperative to examine the impact of compounds within mixtures due to the potential interactions with biological structures which could induce remarkable changes to the toxicity level of a single xenobiotic [Hernando et al., 2003].

The studies in aqueous media are a positive approach to evaluate a the capacity of a microorganism to effectively use a compound included in the substrate either as a sole carbon source or a growth supporting medium [Juhasz and Naidu, 2000]. The literature review revealed both success and failure when species, able to perform degradation of pesticides in aqueous culture, were imported into the soil [Shelton et al., 1996]. Many workers concluded to accordance between investigations on biodegradation in liquid media and bioremediation research in soil. Xenobiotics such as chlorinated pyridinol [Feng et al., 1997] and atrazine [Topp, 2001; Bastos and Magan, 2009] were efficiently depleted from soil and liquid matrices using microorganisms as degraders. In order to achieve the removal of the pentachlorophenol wood preservative from both aqueous culture and soil, Lamar et al. [1990] concluded that Phanerochaete sordida was more effective in a liquid medium while Phanerochaete chrysosporium presented better efficiency in soil. All the afore-mentioned findings suggest that a reliable prediction could be provided relative to the environments in which species will be effective pesticide-degraders.

Despite many literature reports investigated the ability of WRF to degrade single pesticides [Getenga et al., 2000; Maloney, 2001; Xu, 2007; Bastos and Magan, 2009; Gouma et al., 2014], very few have focussed on their degradative abilities concerning the mixture of pesticides as well as the response of these species under the interactions within mixed chemicals [Fragoeiro and Magan, 2008; Chu, 2008; Swarcewicz and Gregorczyk, 2012]. In this study, $P$. coccineus, $P$. gigantea and $T$. versicolor showed a great ability to grow efficiently with the varying concentrations of pesticides combination, in a low nutrient status substrate.

Degradation of chlorpyrifos considerably varied among the fungal species as well as the range of its concentrations. P. coccineus succeed to remove this chemical compound almost at $50 \%$, even at the highest dose of $50 \mathrm{mg} \mathrm{L}^{-1}$ of the mixture, whereas the other two fungi did not provide efficient degradation of high concentrations of chlorpyrifos. Many studies reported chlorpyrifos depletion by several fungi and bacteria. P. chrysosporium was found to successfully mineralize chlorpyrifos [Bumpus et al., 1993]. Moreover, Xu et al. [2007] recorded that Paracoccus sp. strain TRP entirely depleted both chlorpyrifos and its metabolite TCP. Hypholoma fasciculare and Coriolus versicolor presented partial degradation of the poorly available chlorpyrifos in a biobed system [Bending et al., 2002]. Furthermore, Penicillium brevicompactum, Trichoderma harzianum and several Aspergillus species found to exploit chlorpyrifos as both sulphur and phosphorus source [Omar, 1998].

All tested fungal inoculants failed to degrade metribuzin, even though they appeared tolerant with noticeably high $\mathrm{EC}_{50}$ values, as well. A possible explanation could be the short duration (21 days) of the specific experiment so that detoxification of metribuzin was not achieved. The statement above is advocated by the fact that four weeks incubation time required in liquid medium as well, for Rhizopus japonicus and Cunninghamella echinulata to transform metribuzin and to succeed a degradation rate of 27 to $45 \%$ by $F u$ sarium oxysporum, Penicillium lilacinum and Aspergillus niger [Schilling et al., 1985]. Moreover, in aquatic culture studies metribuzin removal of more than $50 \%$ obtained by exclusively three from 53 tested fungal inoculants (Apsidia fusca, Botrytis cinerea and Sordaria superba) [Bordjiba et al., 2001].

$T$.versicolor presented the biodegradable efficacy of linuron, even at the concentration of $50 \mathrm{mg} \mathrm{L}^{-1}$ of its mixture. Besides, the same isolate was an efficient degrader of dieldrin, simazine and trifluralin enhanced by the ability to express a rate of extracellular enzymes [Fragoeiro and Magan, 2008]. Furthermore, Caux [1998] stated that biodegradation is the most important mecha- 
nism for linuron dissipation from soil. Many research studies demonstrated that microorganisms consortia rapidly mineralized linuron partially or even completely. Many of them supported that consortia used this pesticide as the sole source of nitrogen and carbon [Dejonghe, 2003; Sorensen et al., 2005; Danilovic et al., 2015].

In an attempt to find potential ligninolytic enzymes production by the tested fungi total lignolytic activity and polyphenol oxidase assays were used, as they give basic knowledge on the activity of the total enzymes implicated in lignin degradation. The outcomes from the Petri plate assay concerning polyphenol oxidase activity [Rigling,1995] were notable, as all tested isolates (P. coccineus, $P$. gigantea and T. Versicolor) were capable to develop lignolytic activity in all the pesticide treatments.

$T$. versicolor exhibited the greatest laccase activity under the conditions of this assay and it was less affected by pesticide concentrations. Only this fungus produced lignolytic enzymes [Sundman and Nase, 1971] compared to the others, although they had a very good growth, under the conditions of this trial. Haars et al. [1982] reported that this assay is a simple plate test for direct visualization of biological lignin degradation based on the detection of only phenolic groups with ferrichloride-potassium-ferricyanide and possibly explains the ligninolytic enzymes absence. Moreover, positive growth but negative enzyme results could be due to the lack of enzyme production, the production but not release from the mycelium, the production and release but inhibition of detection by the medium, the fungus capability to utilise other materials in the medium in preference to the test substrate, or the fungus growing solely from the carbon source in the inoculum discs [Abdel-Raheem and Shearer, 2002]. Therefore, the absence of a reaction does not mean that species are unable to produce enzymes.

\section{CONCLUSION}

We conclude that the WRF $P$. coccineus, $P$. gigantea and T. versicolor produce high levels of polyphenol oxidase and have the capacity to tolerate and degrade mixtures of pesticides even under cultivation on weak media. These fungi are suggested for potential applications in bioremediation.

\section{REFERENCES}

1. Abdel-Raheem A., Shearer C.A. 2002. Extracellular enzyme production by fresh water ascomycetes. Fungal Diversity, 11, 1-19.

2. Asgher M., Bhatti H.N., Ashraf M., Legge R.L. 2008. Recent developments in biodegradation of industrial pollutants by white rot fungi and their enzyme system. Biodegradation, 19, 771-783.

3. Bastos A.C., Magan N. 2009. Trametes versicolor: potential for atrazine bioremediation in calcareous clay soil, under low water availability conditions. International Biodeterioration and Biodegradation, 63, 389-394.

4. Bending G.D., Friloux M., Walker A. 2002. Degradation of contrasting pesticides by white rot fungi and its relationship with ligninolytic potential. FEMS Microbiology Letters, 212, 59-63.

5. Bordjiba Q., Steiman R., Kadri M., Semadi A., Guiraud P. 2001. Removal of Herbicides from Liquid Media by Fungi Isolated from a Contaminated Soil. Journal of Environmental Quality, 30, 418-426.

6. Bumpus A., Kakar S.N., Coleman R.D. 1993. Fungal degradation of organophosphorus insecticides. Applied biochemistry and biotechnology, 39/40, 715-726.

7. Caux P.Y., Kent R.A., Fan G.T., Grande C. 1998. Canadian water quality guidelines for linuron. Environmental Toxicology and Water Quality, 13, 1-41.

8. Chu X., Fang H., Pan X., Wang X., Shan M., Feng B., Yu Y. 2008. Degradation of chlorpyrifos alone and in combination with chlorothalonil and their effects on soil microbial populations. Journal of Environmental Sciences, 20, 464-469.

9. Danilovic G.M., Curcic N.Z., Pucarevic M.M., Jovanovic L.B., Vagvolgyi C., Kredics L., Pankovic D.M. 2015. Degradation of linuron in soil by two fungal strains. J Nat Sci, Matica Srpska Novi Sad, 129, 45-54.

10. Dejonghe W., Berteloot E., Goris J., Boon N., Crul K., Maertens S., Höfte M., Vos P.D., Verstraete W., Top E.M. 2003. Synergistic degradation of linuron by a bacterial consortium and isolation of a single linuron-degrading Variovorax strain. Applied and Environmental Microbiology, 69, 1532-1541.

11. Extoxnet. 1993. Pesticide Information Profiles (PIPs). Available at http://extoxnet.orst.edu/pips/ ghindex.html.

12. Feng Y., Racke K.D., Bollag J.M. 1997. Isolation and characterization of a chlorinated pyridinol degrading bacterium. Applied and Environmental Microbiology, 63, 4096-4098.

13. Fragoeiro S., Magan N. 2008. Impact of Trametes versicolor and Phanerochaete chrysosporium on differential breakdown of pesticide mixtures in soil microcosms at two water potentials and associated respiration and enzyme activity. International Biodeterioration and Biodegradation, 62, 376-383. 
14. Getenga Z.M., Jondiko J.I., Wandiga S.O., Beck E. 2000. Dissipation behavior of malathion and dimethoate residues from the soil and their uptake by garden pea (Pisum sativum). Bulletin of Environmental Contamination and Toxicology, 64, 359-367.

15. Gianfreda L., Bollag J. 2002. Isolated enzymes for the transformation and detoxification of organic pollutant. In: Enzymes in the environment: activity, ecology, and applications. Burns R., Dick R., Marcel Dekker, New York, USA, pp. 495-538.

16. Gouma S., Fragoeiro S., Bastos A.C., Magan N. 2014. Bacterial and fungal bioremediation strategies. In: Microbial Biodegradation and Bioremediation. Das S., Elsevier Inc., pp. 301-323.

17. Haars A., Milstein O., Lohner S., Hüttermann A. 1982. Rapid, sensitive, and iInexpensive assay for the determination of lignin degradation using different flourescence labelled lignin derivatives. Holzforschung, 36, 85-91.

18. Hernando M.D., Ejerhoon M., Fernández-Alba A.R., Chisti Y. 2003. Combined toxicity effects of MTBE and pesticides measured with Vibrio fischeri and Daphnia magna bioassays. Water Research, 37, 4091-4098.

19. Juhasz A.L., Naidu R. 2000. Bioremediation of high molecular weight polycyclic aromatic hydrocarbons: a review of the microbial degradation of benzo[a]pyrene. International Biodeterioration and Biodegradation, 45, 5-88.

20. Koroleva O.V., Zherdev A.V., Kulikova N.A. 2015. The Role of White-rot Fungi in Herbicide Transformation. In: Herbicides, Physiology of Action, and Safety. Price A., Kelton J., Sarunaite L., InTechOpen., pp. 187-221.

21. Lamar R.T., Larsen M.J., Kirk T.K. 1990. Sensitivity to and degradation of pentachlorophenol by Phanerochaete spp. Applied and Environmental Microbiology, 56, 3519-26.

22. Magan N., Lacey J. 1984. Effect of water activity, temperature and substrate on interactions between field and storage fungi. Trans. Br. Mycol. Soc. 82, 83-93.

23. Maloney S. 2001. Pesticide degradation. In: Fungi in bioremediation. Gadd G., Cambridge University Press, Cambridge, pp. 188-223.

24. Ogunbayo A., Olanipekun O.O., Owoade A.H. 2018. Biodegradation of certain polycyclic hydrocarbons with Paenbacillus alvei and Penicillum restricum. Journal of Ecological Engineering, 19(2), 140-148.

25. Omar S.A., Abdel-Sater A. 2001. Microbial populations and enzyme activities in soil treated with pesticides. Water Air and Soil Pollution, 127, 49-63.

26. Pointing S.B. 2001. Feasibility of bioremediation by white rot fungi. Applied Microbiology and Biotechnology, 57, 20-33.

27. Reddy C.A., Mathew Z. 2001. Bioremediation potential of white rot fungi. In Fungi in bioremediation. Gadd G., Cambridge University Press, Cam- bridge, pp. 52-78.

28. Rigling D. 1995. Isolation and characterization of Cryphonectria parasitica mutants that mimic a specific effect of hypovirulence-associated dsRNA on laccase activity. Canadian Journal of Botany, 73, 1655-1661.

29. Sasek V. 2003. Why mycoremediations have not yet come to practice. In: The utilization of bioremediation to reduce soil contamination: Problems and solutions. Sasek V., Glaser J.A. Baveye P., Springer, Netherlands, pp. 247-276.

30. Schilling R., Engelhardt G., Wallnofer P.R. 1985. Degradation of herbicide metribuzin (sencor) by pure cultures of Cunninghamella echinulata Thaxter ATCC38447. Chemosphere, 14, 267-270.

31. Shelton D.R., Khader S., Karns J.S., Pogell B.M. 1996. Metabolism of twelve herbicides by Streptomyces. Biodegradation, 7, 129-136.

32. Singh B.K., Walker A., Denis J., Wright D.J. 2006. Bioremedial potential of fenamiphos and chlorpyrifos degrading isolates: influence of different environmental conditions. Soil Biology and Biochemistry, 38, 2682-2693.

33. Singleton I. 1994. Microbial metabolism of xenobiotics: Fundamental and applied research. Journal of Chemical Technology and Biotechnology. 59, 9-23.

34. Singleton I. 2001. Fungal remediation of soils contaminated with persistent organic pollutants. In: Fungi in bioremediation. Gadd G., Cambridge University Press, Cambridge, pp. 79-96.

35. Sorensen S.R., Rasmussen J., Carsten S., Ole S., Jacobsen J., Aamand J. 2005. Elucidating the Key Member of a Linuron-Mineralizing Bacterial Community by PCR and Reverse TranscriptionPCR Denaturing Gradient Gel Electrophoresis 16S rRNA Gene Fingerprinting and Cultivation. Applied and Environmental Microbiology, 71, 4144-4148.

36. Sundman V., Nase L. 1971. A simple plate test for direct visualization of biological lignin degradation. Paper and Timber, 53, 67-71.

37. Swarcewicz M.K., Gregorczyk A. 2012. The effects of pesticide mixtures on degradation of pendimethalin in soils. Environmental Monitoring and Assessment, 184, 3077-3084.

38. Topp E. 2001. A comparison of three atrazinedegrading bacteria for soil bioremediation. Biology and Fertility of Soils, 33, 529-534.

39. Xu G., Zheng W., Li Y., Wang S., Zhang J., Yan Y. 2007. Biodegradation of chlorpyrifos and 3,5,6-trichloro-2-pyridinol by a newly isolated Paracoccus sp. strain TRP. International Biodeterioration and Biodegradation, 62, 51-56.

40. Yang C., Liu N., Guo X., Qiao C. 2006. Cloning of mpd gene from a chlorpyrifos-degrading bacterium and use of this strain in bioremediation of contaminated soil. FEMS Microbiology Letters, $265,118-125$. 